\title{
The norite belt in the Mesoarchaean Maniitsoq structure, southern West Greenland: conduit-type Ni-Cu minerali- sation in impact-triggered, mantle-derived intrusions?
}

\author{
Adam A. Garde, John Pattison, Thomas F. Kokfelt, lain McDonald and Karsten Secher
}

With the recent discovery of the giant, deeply eroded, $3 \mathrm{Ga}$ Maniitsoq impact structure in southern West Greenland (Garde 2010), an enigmatic, c. 75 by $15 \mathrm{~km}$ large, curvilinear belt of undeformed norite intrusions with $\mathrm{Ni}$ - $\mathrm{Cu}$ mineralisation was re-interpreted as representing crustally contaminated melts derived from the mantle in the wake of the impact (Fig. 1; Garde et al. 2012). The norite belt (Nielsen 1976; Secher 1983) was discovered in the early 1960s by the mining and exploration company Kryolitselskabet Øresund A/S, and more than one hundred shallow exploration holes were drilled by the company in the period 1965-1971. The mineralisation has subsequently been investigated by Cominco Ltd., Falconbridge Ltd. and NunaMinerals A/S. In 2011, the re-interpretation of the norite belt, and recent availability of improved airborne geophysical exploration tools, prompted the Canadian company North American Nickel Inc. (NAN) to resume exploration.

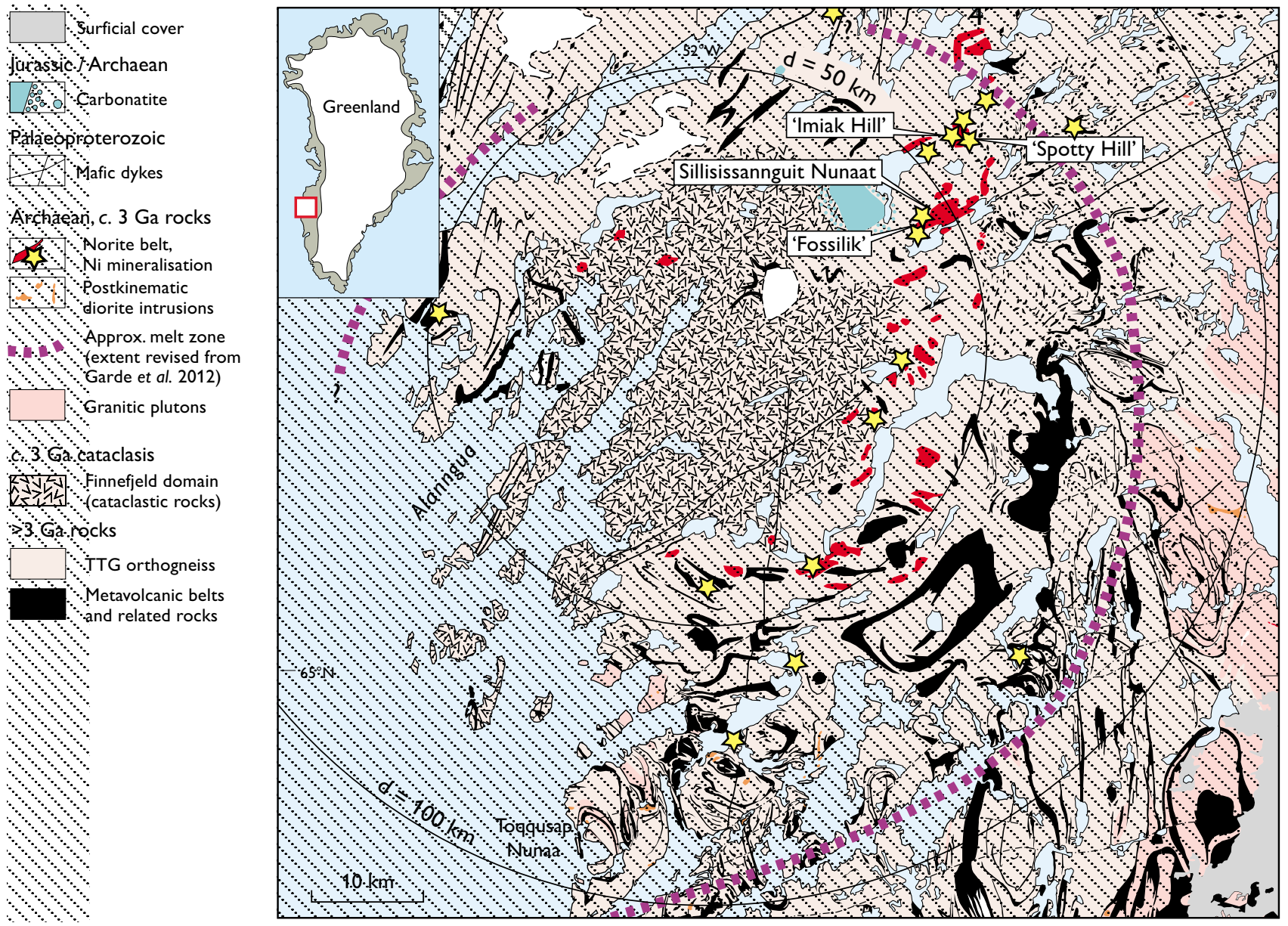

Fig. 1. Geological map of the central part of the Maniitsoq impact structure with the cataclastic Finnefjeld domain in its centre, currently known distribution of norites and postkinematic diorites, and three labelled diamond drilling sites from 2012. Reference circles with 50 and $100 \mathrm{~km} \mathrm{diameters} \mathrm{are} \mathrm{shown.}$ 


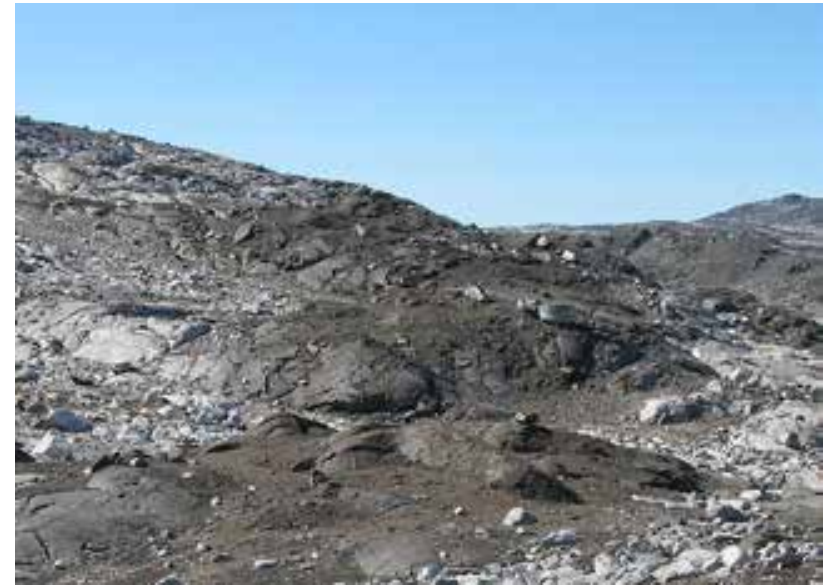

Fig. 2. Typical homogeneous, undeformed norite outcrop with diffuse, hybridised contact zones to quartzo-feldspathic orthogneiss. From Garde et al. (2012).

This contribution gives a short description of the norite belt, outlines its $\mathrm{Ni}-\mathrm{Cu}$ mineralisation and presents a preliminary interpretation. It is well known that the $1.85 \mathrm{Ga}$ Sudbury impact structure in Canada hosts a group of worldclass $\mathrm{Ni}-\mathrm{Cu}$ deposits at the base of the impact melt sheet (Eckstrand \& Hulbert 2007). The Ni-Cu mineralisation of the norite belt in West Greenland is profoundly different as it is located in lower-crustal mafic intrusions, but we suggest here that also this was governed by impact-related magmatic processes.

\section{The Maniitsoq structure}

The Maniitsoq structure (Garde et al. 2012) constitutes the deeply eroded, deep-crustal remains of a giant extraterres-

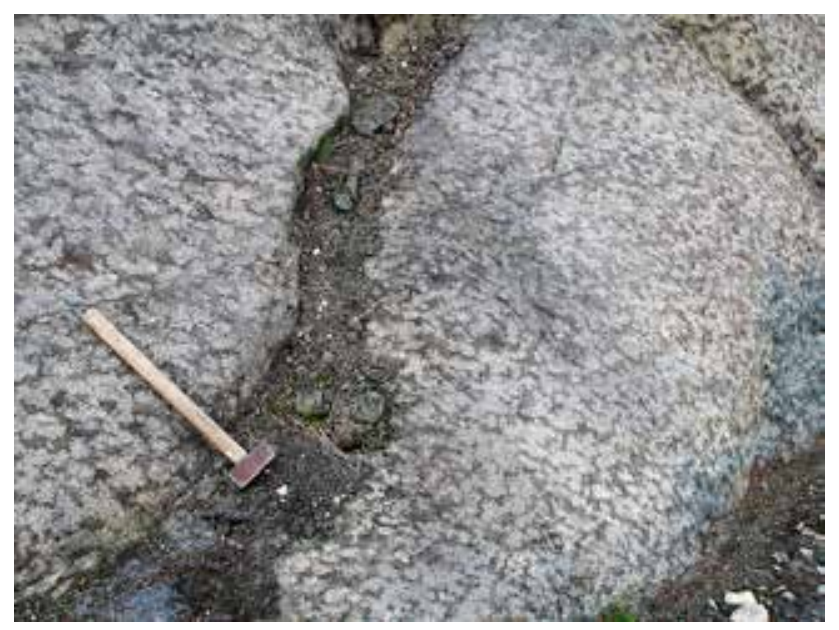

Fig. 3. Proto-orbicular texture in norite, with rounded, skeletal plagioclase crystals and interstitial hypersthene. The hammer is $45 \mathrm{~cm}$ long. trial impact that struck an active magmatic arc $3 \mathrm{Ga}$ ago in the north-central part of the North Atlantic craton (Fig. 1). The visible remains of the structure comprise a core measuring 35 by $50 \mathrm{~km}$ of thoroughly crushed, mechanically mixed and subsequently welded fragments of orthogneiss and amphibolite (together constituting the Finnefjeld domain), surrounded by an up to $c .75 \mathrm{~km}$ wide, annular melt zone variably affected by both crushing and melting, and a peripheral, less damaged zone with a diameter of approximately 150 $\mathrm{km}$. Large parts of the entire structure have been affected by intense hydrothermal alteration and related, fluid-induced, partial melting. These features, and their large geographical extent, suggest that the original Maniitsoq crater was larger than all previously known terrestrial impact structures.

\section{The norite belt and postkinematic diorites}

The norite belt (see above) and associated postkinematic diorites in the southern part of the impact structure (Berthelsen 1960; Garde 1991) collectively comprise numerous mafic to ultramafic intrusions ranging in size from small dykes to inclined, elongate bodies up to several square kilometres in outcrop size, hosted by Mesoarchaean orthogneisses and mafic, metavolcanic belts. They were emplaced close to 3.0 Ga ago (see Garde et al. 2012), and their undeformed state and occasional xenoliths of crushed orthogneiss and fluidised microbreccia document that they post-date the impact. The intrusions are locally cut by few centimetres thick, white, undeformed pegmatites. Most intrusions display inclined hostrock contacts, and the exposed bodies may thus represent open-ended magma conduits. The hybridised contact zones are diffuse, up to about $10 \mathrm{~m}$ wide and commonly hydrated (Fig. 2). The known extent of the norite belt is shown on Fig. 1 , but at least a few additional, unmapped bodies are known to occur east and west of the main belt. The postkinematic diorites have a more random distribution and extend up to c. $70 \mathrm{~km}$ south and east of the centre of the impact structure. They have only been mapped systematically south of $65^{\circ} \mathrm{N}$.

The noritic and dioritic rocks typically form dark brown, crumbly weathering, medium- to coarse-grained, mostly structureless masses. They largely consist of variable proportions of orthopyroxene and andesine plagioclase with medium- to coarse-grained, granular textures. Rhythmic magmatic layering is rare, but has been observed, e.g. at Sillisissannguit Nunaat (Fig. 1; Secher 1983). Both small and large intrusions locally display proto-orbicular quench textures comprised of skeletal, rounded to ellipsoidal plagioclase crystals up to about $10 \mathrm{~cm}$ in size, and interstitial orthopyroxene (Fig. 3), and locally display metre-scale layering. Bulk compositions cover a large range from dioritic to 
noritic, but display a broadly uniform trace element distribution pattern; high $\mathrm{MgO}, \mathrm{Cr}$ and $\mathrm{Ni}$ contents ( $\leq 21 \mathrm{wt} \%, 3685$ ppm and 909 ppm, respectively) coupled with low $\mathrm{Nb}$ and $\mathrm{Ta}$ suggest an ultramafic precursor affected by abundant crustal contamination (Garde 1991; Garde et al. 2012).

\section{$\mathrm{Ni}-\mathrm{Cu}$ mineralisation}

More than 50 sulphide-mineralised norite localities with uniform characteristics have been investigated over time (Nielsen 1976; unpublished company reports). In typical, two-dimensional outcrops, the mineralised rocks form isolated, rusty weathered spots and lenses that rarely exceed $25 \mathrm{~m}$ in length (Secher 1983). The sulphide paragenesis in fresh samples is almost invariably pyrrhotite-pentlanditechalcopyrite-pyrite, with accessory magnetite and ilmenite. The sulphide minerals form interconnected, semi-massive networks with inclusion-bearing, breccia-like textures characterised by rounded, centimetre-sized and larger lumps of the host rock (Fig. 4). These textures closely resemble those found in magmatic, conduit-type Ni deposits such as Noril'sk in Russia and Lynn Lake and Voisey's Bay in Canada (Eckstrand \& Hulbert 2007).

All significant nickel occurrences discovered to date at Maniitsoq are entirely contained within norite intrusions. Based on NAN's diamond drilling, combined with historical drill-hole information and three-dimensional modelling of airborne geophysical and down-hole electromagnetic data, the mineralisation can typically be described as steeply to vertically dipping pipe- and sheet-like bodies comprised of heavily disseminated to near massive sulphide, often with abundant $0.2-5.0 \mathrm{~cm}$ subangular to subrounded inclusions of norite. In most cases, strongly mineralised zones are surrounded by a broad halo of weaker, disseminated mineralisation; however, in some places the contact between near solid sulphide and barren norite host rock is extremely sharp.

Diamond drilling in 2012 was performed at 'Imiak Hill', 'Spotty Hill' and 'Fossilik II' (cf. Fossilik in Fig. 1); the following, generalised figures of metal contents are solely intended to characterise the type of mineralisation without

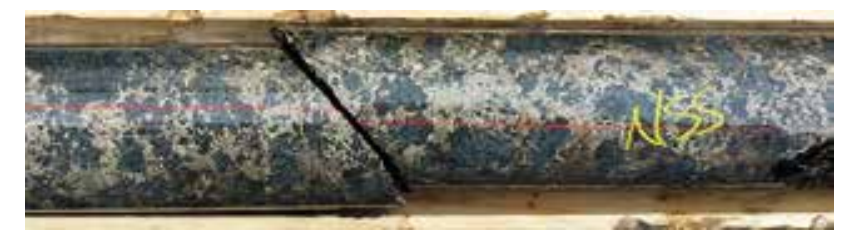

Fig. 4. Inclusion-bearing, breccia-like texture of $\mathrm{Ni}-\mathrm{Cu}$ mineralisation at 'Imiak Hill' (North American Nickel Inc. 2012 drill core MQ-12-002 at $66.55 \mathrm{~m})$.

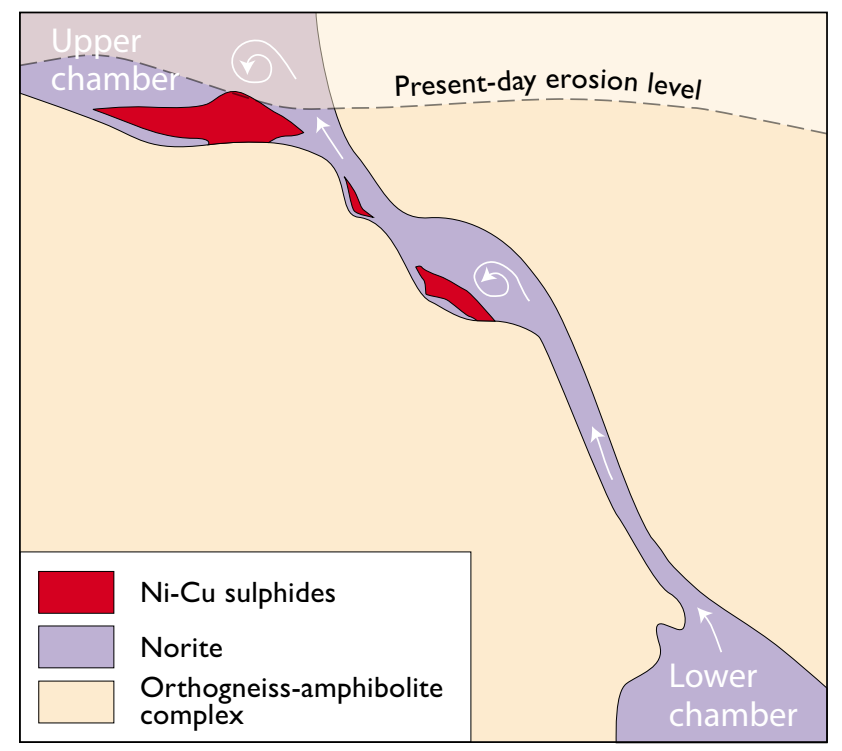

Fig. 5. Magmatic open-conduit model for the $\mathrm{Ni}$-Cu mineralisation in the norite belt. Schematic vertical section. Modified from Maier et al. (2001).

addressing economic aspects. The mineralisation has a high, uniform $\mathrm{Ni}$ tenor averaging 6-9\% Ni recalculated to $100 \%$ sulphide, both at localities previously drilled by Kryolitselskabet Øresund A/S and also in new cores drilled by NAN at 'Imiak Hill' and 'Spotty Hill' in 2012. Typical Ni contents in wt $\%$ of the total rock vary between 1 and $2 \%$ over several to many metres, with additional $0.1-0.6 \% \mathrm{Cu}, 0.01-0.07 \%$ Co, up to $0.2 \mathrm{ppm} \mathrm{Pt}$ and Pd, and Au in the ppb range (data from www.northamericannickel.com and Secher 2001). These relatively low platinum-group element tenors are similar to the Voisey's Bay deposit (Lightfoot et al. 2012).

\section{Discussion and interpretations}

\section{Origin of the noritic and dioritic intrusions}

Garde (1991) and Garde et al. (2012) interpreted the noritic and almost all of the dioritic intrusions as highly unusual, mantle-derived, crustally contaminated ultrabasic melts. This interpretation is based on (1) the wide, hybrid contact zones and (2) proto-orbicular interior textures of skeletal plagioclase and orthopyroxene, showing that the magmas were chilled by their hosts and crystallised rapidly (and thus indicating a very high emplacement temperature), (3) highly variable chemical compositions combined with (4) broadly similar overall element spectra consistent with mantle-crust mixtures, (5) ultramafic trace element signatures with very high $\mathrm{Cr}$, Ni and $\mathrm{V}$ contents, and (6) mantle-like, strongly suprachondritic $\mathrm{Ru} / \mathrm{Ir}, \mathrm{Rh} / \mathrm{Ir}, \mathrm{Pt} / \mathrm{Ir}$ and $\mathrm{Pd} / \mathrm{Ir}$ ratios similar to high-Mg basalts. 


\section{Interpretation of the $\mathrm{Ni}-\mathrm{Cu}(-\mathrm{PGE})$ mineralisation}

Magmatic Ni-Cu-PGE deposits are governed by several different factors (e.g. Li et al. 2001; Maier et al. 2001) including a fertile source (typically the mantle), where a significant $\mathrm{Ni}$ contribution comes from interstitial sulphide minerals in addition to olivine. A high degree of melting is also required in order to ensure a complete dissolution of the sulphides with their metals into the primary magma. On the ascent of the magma, segregation of immiscible, sulphidic melt from the silicate melt must then occur in order to recapture the chalcophile elements of interest. In general terms, such segregation in response to sulphur saturation can be brought about by either fractional crystallisation in large magma chambers (potentially leading to PGE-dominated deposits), or by crustal contamination in dynamic magma channels of restricted volume, potentially leading to $\mathrm{Ni}-\mathrm{Cu}$-dominated deposits (Li et al. 2001). In the latter case, a suitable physical mechanism to separate and concentrate the exsolved, high-density sulphide liquid from the flowing magma is also required.

The essential features of the sulphide occurrences in the norite belt are all compatible with an interpretation as magmatic, open-source mineralisation systems. These features include high-temperature ultramafic host rock melts, abundant field and chemical evidence of crustal contamination, inclusion-bearing, breccia-like textures in the mineralised rocks, a high $\mathrm{Ni}$ tenor in the sulphides, and $\mathrm{Ni} / \mathrm{Cu}$ and $(\mathrm{Ni}+$ $\mathrm{Cu}) / \mathrm{PGE}$ ratios characteristic of this type of mineralisation. The three-dimensional shapes of the mineralised volumes and mechanism(s) of physical extraction of the exsolved sulphide melt phase are currently poorly known, but a schematic section of a possible scenario is shown in Fig. 5.

\section{Concluding remarks}

Widespread ultramafic magmatism, such as in the norite belt, does not belong in convergent orogenic systems (Garde 1991; Garde et al. 2012), although ultramafic intrusions can occur under special plate-tectonic circumstances of ridge subduction or delamination of the lower crust, for which there is no evidence at Maniitsoq. Furthermore, the protoorbicular textures and very high degrees of contamination in the norite belt and postkinematic diorites are highly unusual even for ultramafic melts.

The possibility of impact-induced mantle melting associated with giant impacts has previously been discussed in the literature (Jones et al. 2002), but no examples have been found prior to the case at Maniitsoq (see Garde et al. 2012). We conclude that the $\mathrm{Ni}-\mathrm{Cu}$ occurrences in the norite belt are likely an impact-induced mineralisation. However, unlike Sudbury they are not part of a differentiated impact melt sheet, but constitute a special variety of open-conduit systems, which are otherwise known from magmatic settings of non-impact origin.

\section{References}

Berthelsen, A. 1960: Structural studies in the pre-Cambrian of western Greenland. II. Geology of Tovqussap nunâ. Bulletin Grønlands Geologiske Undersøgelse 25, 223 pp.

Eckstrand, O.R. \& Hulbert, L.J. 2007: Magmatic nickel-copper-platinum group element deposits. In: Goodfellow, W.D. (ed.): Mineral deposits of Canada: a synthesis of major deposit types, district metallogeny, the evolution of geological provinces, and exploration methods. Geological Association of Canada Special Publication 5, 205-222.

Garde, A.A. 1991: Post-kinematic diorite intrusions in Archaean basement rocks around outer Fiskefjord, southern West Greenland. Bulletin of the Geological Society of Denmark 39, 167-177.

Garde, A.A. 2010: The 2975 Ma Maniitsoq impact structure in West Greenland: the oldest and most deeply exposed meteorite crater on Earth. Abstracts and Proceedings of the Geological Society of Norway 1, 57-58.

Garde A.A., McDonald, I., Dyck, B. \& Keulen, N. 2012: Searching for giant, ancient impact structures on Earth: the Mesoarchaean Maniitsoq structure, West Greenland. Earth and Planetary Science Letters 337-338, 197-210.

Jones, A.P., Price, G.D., Price, N.J., De Carli, P.S. \& Clegg, R.A. 2002:Impact induced melting and the development of large igneous provinces. Earth and Planetary Science Letters 202, 551-561.

Li, C., Maier, W.D. \& de Waal, S.A. 2001: Magmatic Ni-Cu versus PGE deposits: contrasting genetic models and exploration implications. South African Journal of Geology 104, 309-318.

Lightfoot, P.C., Keays, R.R., Evans-Lamswood, D. \& Wheeler, R. 2012: Saturation history of Nain Plutonic Suite mafic intrusions: origin of the Voisey's Bay Ni-Cu-Co sulfide deposit, Labrador, Canada. Mineralium Deposita 47, 23-50.

Maier, W.D., Li, C. \& de Waal, S.A. 2001: Why are there no major Ni-Cu sulfide deposits in large layered mafic-ultramafic intrusions? Canadian Mineralogist 39, 547-556.

Nielsen, B.L. 1976: Economic minerals. In: Escher, A. \& Watt, W.S. (eds): Geology of Greenland, 460-487. Copenhagen: Geological Survey of Greenland.

Secher, K. 1983: Noritic rocks and associated nickel-copper-sulphide occurrences in Sukkertoppen district, central West Greenland. Rapport Grønlands Geologiske Undersøgelse 115, 30-34.

Secher, K. 2001: The Pd+Pt dispersion in noritic and undifferentiated mafic rocks of the Archaean craton east of Maniitsoq, southern West Greenland. Danmarks og Grønlands Geologiske Undersøgelse Rapport 2001/123, 22 pp.

\footnotetext{
Authors' addresses

A.A.G., T.F.K. \& K.S., Geological Survey of Denmark and Greenland, Øster Voldgade 10, DK-1350 Copenhagen K, Denmark. E-mail: aag@geus.dk J.P., North American Nickel Inc., 301-260 W. Esplanade, North Vancouver, BC V7M 3G7, Canada.

I.McD., School of Earth and Ocean Sciences, Cardiff University, P.O. Box 914, Cardiff CF10 3YE, UK.
} 